\title{
SHEAR BOND STRENGTH OF RESIN MODIFIED GLASS IONOMER FILLING MATERIAL IN PRIMARY MOLARS PREPARED BY BOND PREP MODE AND CUTTING MODE ER,CR:YSGG LASER (AN IN VITRO STUDY)
}

\author{
Ayman Abdel Hamid Abdallah Sabah*
}

\begin{abstract}
Introduction: The family of erbium laser which has two different wavelengths including Er:YAG laser $(2940 \mathrm{~nm})$ and Er,Cr:YSGG laser $(2780 \mathrm{~nm})$ is an effective device for cutting dental hard tissue due to their high absorption in water and hydroxyapatite that makes them suitable for cavity preparation. Cavity preparation using laser has some advantages such as reduced pain and vibration during the procedure and providing patient's comfort which is the key factor in pediatric dentistry.
\end{abstract}

Materials and methods: The purpose of the present study is to compare and evaluate the effect bond prep mode and cutting mode of Er,Cr:YSGG Laser on shear bond strength of glass ionomer (GI) cement and resin modified glass ionomer (RMGI) filling materials applied on flattened buccal and lingual surface on forty-eight freshly extracted caries-free human primary molars divided into 2 groups and each group is subdivided into 2 subgroups each according to the mode of preparation: group 1: bond prep mode Er,Cr:YSGG laser; group 2: Er,Cr:YSGG cutting mode. The samples will be subjected to universal testing machine.

Results: The mean (SD) values for shear bond strength of Bond prep and cutting modes regardless of restorative material were 22.9 (5.3) and 20.7 (5.2), respectively. There was no statistically significant difference between the two preparation modes. There was no statistically significant difference between Bond prep and cutting modes whether using GI ( $\mathrm{P}$-value $=0.433$, Effect size $=0.014)$ or with RMGI (P-value $=0.051$, Effect size $=0.085)$. Comparison between the two restorative materials revealed that GI showed statistically significantly lower mean shear bond strength than RMGI whether using Bond prep mode (P-value $<0.001$, Effect size $=0.345$ ) or cutting mode $(\mathrm{P}$-value $=0.001$, Effect size $=0.226)$.

Conclusion: Er,Cr:YSGG laser have adverse effect on the adhesion of RMGI and GI, bond prep mode is better than cutting mode and RMGI is preferred than GI clinically.

KEY WORDS: Shear bond strength, Er,Cr:YSGG Laser, bond prep mode, resin modified glass ionomer

* Lecturer Pediatric Dentistry and Orthodontic Department, Faculty of Oral and Dental medicine, Misr International University 


\section{INTRODUCTION}

Minimally invasive dentistry had gained wider acceptance with the advance of new dental adhesive systems and technical advances in tools for the dental hard tissue operations ${ }^{1,2}$ and due to alternative methods of cavity preparation and manipulation of the dental hard tissue ${ }^{3,4}$, the erbium: yttrium aluminum garnet (Er:YAG) $(2.94 \mu \mathrm{m})$ and erbium, chromium: yttrium-scandium-gallium garnet (Er,Cr:YSGG) $(2.78 \mu \mathrm{m})$ wavelengths gained wide acceptance, as they were the only erbium lasers available for the dental hard tissue operations by virtue of their high tissue interaction and limited thermal damage to surrounding tissues ${ }^{3,4}$.

Numerous studies have evaluated the immediate bond strengths of current dental adhesive systems to the dental hard tissues irradiated by Er,Cr:YSGG laser, aiming to determine whether Er,Cr:YSGG laser-irradiated dental hard tissues offer a suitable bonding substrate ${ }^{5-7}$. Initial studies revealed that irradiation of the dentin using Er,Cr:YSGG laser leads to increase in surface roughness, with open dentinal tubules and no smear layer on the surface, suggesting that the irradiated dentin might provide a favorable substrate for resin bonding ${ }^{8,9}$. However, bonding to irradiated dentin remains a controversial issue in the literature ${ }^{10-12}$; some studies have reported that Er,Cr:YSGG laser irradiation yields lower initial bond strength to dentin, while others have presented contrary findings ${ }^{8,9}$.

Cavity preparation using laser had some advantages such as reduced pain and vibration during the procedure and providing patient's comfort which is then key factor in pediatric dentistry ${ }^{13-16}$. Different studies have shown that Er: YAG laser can remove smear layer, open dentinal tubules and create a rough surface ${ }^{15-19}$, while some studies have found that these properties have led to better etching techniques and adhesion of bonding material ${ }^{20,21}$, but opposite results have been reported by others ${ }^{15,18}$.
Dentin of the primary tooth had a lower mineralization, higher organic material, and water content compared to the permanent teeth, with low density and thickness of dentinal tubules about 0.4-0.5 $\mathrm{mm}$ to the pulp surface, ${ }^{21}$ so, considering these morphological differences and heterogeneous composition, laser parameter should be set differently in the primary teeth ${ }^{21}$.

Behavior management of the child patient in dentistry had a great challenge, so decreasing the possibilities of failure of fillings in the primary teeth by improving bonding between the tooth and adhesive restorative materials will increase longevity of the primary teeth fillings and hence, minimize the number of dental visits of the child patients, however, few studies were done on laser irradiation in the primary teeth for cavity preparation before adhesive use ${ }^{22}$.

The purpose of the present study is to compare and evaluate the effect of bond prep mode and cutting mode of Er, Cr: YSGG laser in the primary molars on shear bond strength of GI and RMGI filling materials using universal testing machine.

\section{Sample Preparation}

Forty-Eight human unidentified deciduous molars with at least intact one surface buccal or lingual that exfoliated either due to physiologic reason or which are indicated for extraction were selected. Teeth with caries on both buccal and/or lingual surfaces, fractured crown due to extraction, hypoplastic, hypocalcified and of any developmental anomaly were rejected. The teeth were washed under running water, cleaned of residual tissue and debris, then autoclaved and stored in distilled water at $4^{\circ} \mathrm{C}$ for not more than 1 week ${ }^{19,24}$. Forty-Eight deciduous molars were divided into 2 groups and each group is subdivided into 2 subgroups each according to the mode of preparation: group 1: bond prep mode Er,Cr:YSGG laser; group 2: cutting mode Er,Cr:YSGG 


\section{Tooth surface preparation (substrate):}

Forty-eight samples were embedded in acrylic resin in standardized autoclavable Teflon molds. In group 1, buccal surface was flattened (bond prep mode) with Er,Cr:YSGG laser (Waterlase iPlus, Biolase; Irvine, CA,USA) using a Waterlase iplus Gold handpiece and aMGG6 tapered sapphire tip having a fiber core diameter of $600 \mu \mathrm{m}$. The laser settings were $4.5 \mathrm{~W}$ (peak power), frequency $50 \mathrm{~Hz}$, air pressure $60 \%$, and water pressure $80 \%$, used in noncontact mode in 24 samples. In group 1a (12 samples) GI using Harvard ionoglass Cem (Harvard Dental International $\mathrm{GmbH}$ Margarentenstr, 2-4 15366 Hoppegarten, Germany) was applied on prepared surfaces of dentin. In group $1 \mathrm{~b}$ (12 samples) RMGI using GC Fuji II LC Capsule (GC Corporation Tokyo, Japan) was applied on prepared surfaces of dentin. For group 2, lingual surface was roughened (cutting mode) with Er,Cr:YSGG laser (Waterlase iPlus, Biolase; Irvine, CA,USA) using a Waterlase iplus Gold handpiece and aMGG6 tapered sapphire tip having a fiber core diameter of $600 \mu \mathrm{m}$ till yellow dentin was seen. The laser settings were6 $\mathrm{W}$ (peak power), frequency $15 \mathrm{~Hz}$, air pressure $60 \%$, and water pressure $80 \%$ in 24 samples. In group 2a (12 samples) GI using Harvard ionoglass Cem (Harvard Dental International GmbH Margarentenstr, 2-4 15366 Hoppegarten, Germany) was applied on prepared surfaces of dentin. In group 2b (12 samples) RMGI using GC Fuji II LC Capsule (GC Corporation Tokyo, Japan) was applied on prepared surfaces of dentin.

\section{Restorative Material Application}

Standardized cylinders of GI and RMGI filling materials were applied to the prepared surfaces of dentin by the aid of a specially designed Teflon mold with standardized dimension.

\section{Shear Bond Strength Testing}

All samples of groups 1a, 1b, 2a, and 2b were subjected to shear bond strength test using Instron universal testing machine (Instron, Norwood, USA) at a cross head speed of $0.5 \mathrm{~mm} / \mathrm{min}$ until fracture. The specimen was placed in the lower assembly of the machine and the force was applied with the help of a knife-like mandrel which engages the cylinders of GI and RMGI at the tooth restoration interface to test the strength of the bond. Data were recorded using BlueHill computer software.

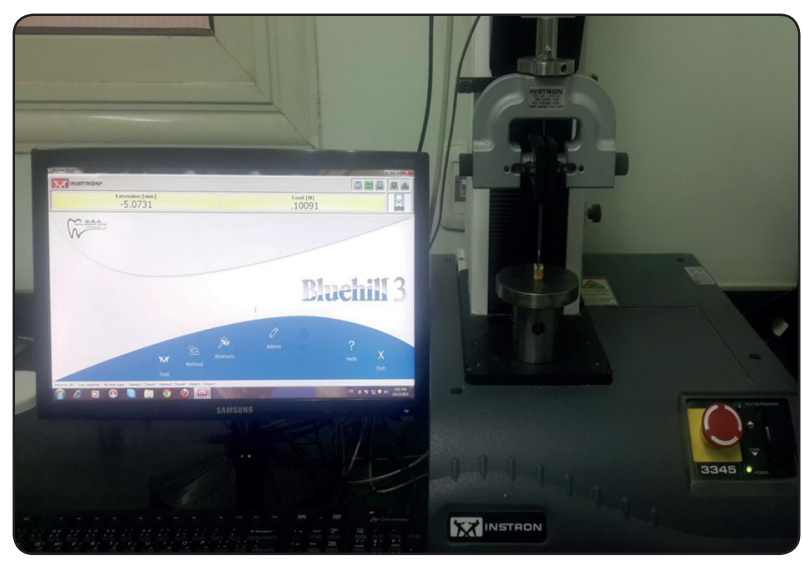

Fig. (1): Universal testing machine (Instron, Norwood, USA)

\section{Statistical Analysis}

Quantitative data was presented as mean, median, standard deviation (SD), range (Minimum - Maximum) and 95\% Confidence interval (95\% CI) for the mean values. Data was explored for normality by checking the data distribution, calculating the mean and median values and using Kolmogorov-Smirnov and Shapiro-Wilk tests. For parametric data, two-way Analysis of Variance (ANOVA) was used to study the effect of preparation method, material and their interaction on mean shear bond strength. Bonferroni's posthoc test was used for pair-wise comparisons when ANOVA test was significant. For non-parametric data; Mann-Whitney U test was used to compare between the two preparation methods as well as the two restorative materials. The significance level was set at $\mathrm{P} \leq 0.05$. Statistical analysis was performed with IBM ${ }^{\circledR}$ SPSS $^{\circledR}$ Statistics Version 20 for Windows (SPSS, Inc., an IBM Company). 


\section{RESULTS}

Descriptive statistics for shear bond strength values (MPa) in the different groups are presented in Table 1. Two-way ANOVA results showed that regardless of restorative material; preparation mode had no statistically significant effect on mean shear bond strength $(P$-value $=0.053$, Effect size $=$ 0.082). Regardless of preparation mode; restorative material had a statistically significant effect on mean shear bond strength $(P$-value $<0.001$, Effect size $=$ $0.444)$. The interaction between the two variables had no statistically significant effect on mean shear bond strength $(P$-value $=0.390$, Effect size $=$ $0.017)$. Since the interaction between the variables is not statistically significant, so the variables are independent from each other (Table 2).

The mean (SD) values for shear bond strength of Bond prep and cutting modes regardless of restorative material were 22.9 (5.3) and 20.7 (5.2), respectively (Figure 2). There was no statistically significant difference between the two preparation modes $(P$-value $=0.053$, Effect size $=0.082)$.

The mean (SD) values for shear bond strength of GI and RMGI regardless of preparation mode were 18.4 (4.2) and 25.2 (4), respectively (Figure 3). GI showed statistically significantly lower mean shear bond strength than RMGI ( $P$-value $<0.001$, Effect size $=0.444)$.

Table 3 represents the interaction of variables. The results showed that there was no statistically significant difference between Bond prep and cutting modes whether using GI $(P$-value $=0.433$, Effect size $=0.014)$ or with RMGI $(P$-value $=0.051$, Effect size $=0.085)$. Comparison between the two restorative materials revealed that GI showed statistically significantly lower mean shear bond strength than RMGI whether using Bond prep mode $(P$-value $<0.001$, Effect size $=0.345)$ or cutting mode $(P$-value $=0.001$, Effect size $=0.226)$.

TABLE (1) Descriptive statistics for shear bond strength values (MPa)

\begin{tabular}{|l|l|c|c|c|c|}
\hline \multirow{2}{*}{$\begin{array}{l}\text { Preparation } \\
\text { mode }\end{array}$} & Restorative material & Mean & \multirow{2}{*}{ SD } & \multicolumn{2}{|c|}{$95 \%$ CI } \\
\cline { 4 - 6 } & & & & Lower bound & Upper bound \\
\hline \multirow{3}{*}{ Bond prep } & GI & 19 & 3.5 & 16.7 & 21.4 \\
\cline { 2 - 6 } & RMGI & 26.8 & 3.5 & 24.5 & 29.2 \\
\hline \multirow{2}{*}{ Cutting } & GI & 17.8 & 3.9 & 15.4 & 20 \\
\cline { 2 - 6 } & RMGI & 23.6 & 3.8 & 21.3 & 25.9 \\
\hline
\end{tabular}

TABLE (2) Two-way ANOVA results for the effect of different variables on mean shear bond strength

\begin{tabular}{|l|c|c|c|c|c|c|}
\hline Source of variation & $\begin{array}{c}\text { Type III Sum } \\
\text { of Squares }\end{array}$ & df & Mean Square & F-value & P-value & $\begin{array}{c}\text { Effect size } \\
\text { (Partial eta squared) }\end{array}$ \\
\hline Preparation mode & 62.3 & 1 & 62.3 & 3.950 & 0.053 & 0.082 \\
\hline Restorative material & 555.6 & 1 & 555.6 & 35.204 & $<0.001^{*}$ & 0.444 \\
\hline $\begin{array}{l}\text { Preparation mode x Restorative } \\
\text { material interaction }\end{array}$ & 11.9 & 1 & 11.9 & 0.754 & 0.390 & 0.017 \\
\hline
\end{tabular}

$d f:$ degrees of freedom $=(n-1), *$ : Significant at $P \leq 0.05$ 
TABLE (3) The mean, standard deviation (SD) values and results of two-way ANOVA test for comparison between shear bond strength values with different interactions

\begin{tabular}{|l|c|c|c|c|c|c|}
\hline \multirow{2}{*}{ Restorative material } & \multicolumn{2}{|c|}{ Bond prep } & \multicolumn{2}{c|}{ Cutting } & \multirow{2}{*}{$\begin{array}{c}\text { P-value (Between } \\
\text { modes) }\end{array}$} & $\begin{array}{c}\text { Effect size (Partial } \\
\text { eta squared) }\end{array}$ \\
\cline { 2 - 6 } GI & Mean & SD & Mean & SD & 0.433 & 0.014 \\
\hline RMGI & 19 & 3.5 & 17.8 & 4.9 & 0.051 & 0.085 \\
\hline P-value (Between materials) & 26.8 & 3.5 & 23.6 & 3.8 & & \\
\hline Effect size (Partial eta squared) & \multicolumn{2}{|c|}{$0.001 *$} & \multicolumn{2}{|c|}{$0.001 *$} & & \\
\hline
\end{tabular}

*: Significant at $P \leq 0.05$

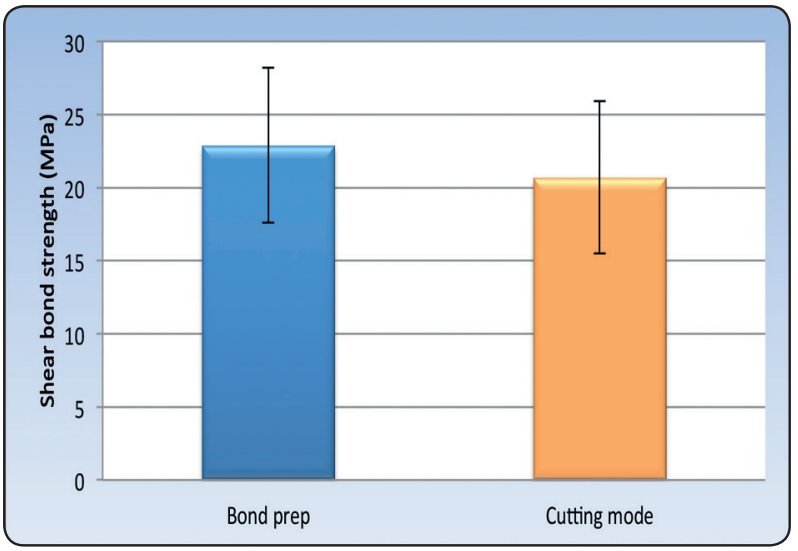

Fig. (2): Mean and standard deviation values for shear bond strength of preparation modes regardless of restorative material

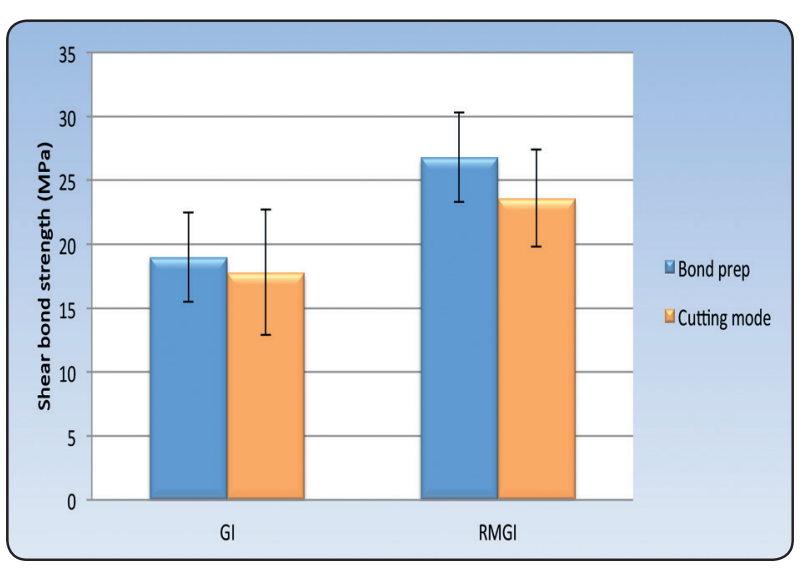

Fig. (4): Mean and standard deviation values for shear bond strength with different interactions of variables

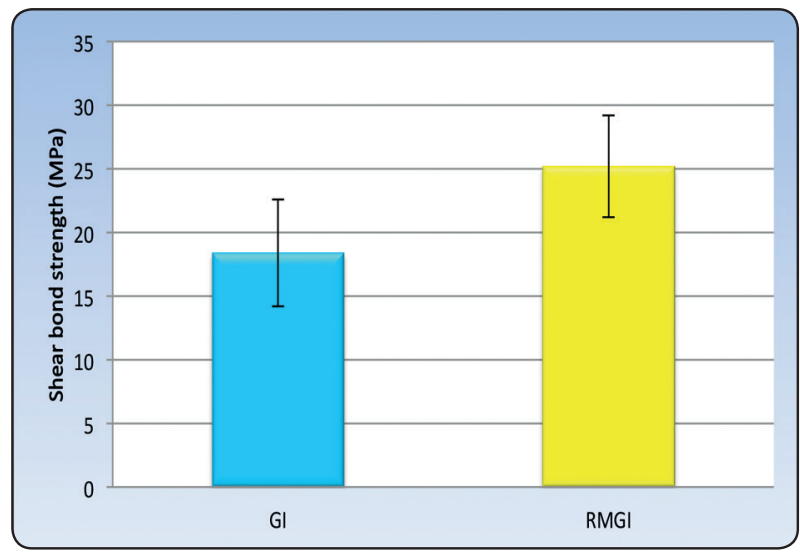

Fig. (3): Mean and standard deviation values for shear bond strength of the two restorative materials regardless of preparation mode

\section{DISCUSSION}

The most important factor for retaining a restoration bonded chemically to the tooth surface such as glass ionomer is the resistance to shear stresses which are the stresses formed at the interface of tooth surface with restoration are caused by parallel or perpendicular forces acting on the tooth surface $^{23}$.

A lot of questions have been raised due to recent developments in the field of laser usage in dentistry regarding the type of laser, characteristics and parameters needed to bond appropriately to the dental tissue. When dentin of the permanent teeth 
was compared to dentin of the primary teeth, it was found that the organic material and water content is high with more irregular dentinal tubules, while the water content in inter-tubular dentin is more than intra-tubular dentin ${ }^{16,24}$ which indicate that when using a laser with similar power, it will remove higher amount of tissue in the deciduous teeth, so lower parameters should be used in the deciduous teeth than those used in the permanent teeth, which may explain why the bond prep showed higher shear bond strength than the cutting mode with both materials where the bond prep results in roughness with no smear layer.

In an in vivo study conducted by Bahrololoomi $\mathrm{Z}$ et al. ${ }^{19}$ stated that shear stresses are forces highly involved in the restorative materials bond failures, and founded that the laser irradiation results in a pattern of adhesion that made the bonding process more improved which agreed with the results of Hossain et al, ${ }^{25}$ Visuriet al, ${ }^{20}$ and Hibst et al, ${ }^{26}$ Wanderly et al, ${ }^{27}$ and Mahmoudianet al, ${ }^{22}$.Sung EC, in his study found that although the usage of different type of laser (Er, Cr: YSGG), the overall result agreed with the results of this study ${ }^{28}$. Armengol et al, ${ }^{29}$ Kataumi et al, ${ }^{30}$ and Burnett et al. ${ }^{31}$ proven that there is no difference in bond strength between irradiated specimens by the Er: YAG laser and control group in their research.

Sakakibara, ${ }^{32}$ Dunn et al, ${ }^{17}$ and Ceballo et al. ${ }^{33}$ have discovered that after laser irradiation low shear bond strength were found, which disagree with the current study. They attributed their findings to that the laser irradiation results in denatured collagen fibers layer with poor adhesion to the surface of dentin which didn't contains peri-fibrillar spaces, that may limit the penetration of resin to subsurface inter-tubular dentin and leads to weak hybrid layer formation. ${ }^{33}$

In a study conducted by Ceballoset al, ${ }^{11}$ Backmann et al, ${ }^{34}$ and Lee et al. ${ }^{9}$ a low shear bond strength of adhesives to the prepared surfaces by the Erbium laser were founded in comparison to prepared surfaces by the diamond burs using highspeed rotary instruments. They discovered that the rise in temperature during ablation melt and vaporize the collagen network of the irradiated tissue, resulting in a modified surface, where the collagen fibers which are denatured coalesce with each other, but attaches poorly to the healthy dentin below area irradiated, so prevent the construction of better hybrid layer at the tooth/restoration interface and thus lowers shear bond strength which may explain the findings of the current study why the bond prep mode with lower watt setting showed higher shear bond strength than the cutting mode.

Glass ionomer cements have raised their usage in pediatric dentistry because of their physicochemical adhesion properties to enamel and dentin ${ }^{35}$. GIallow good adhesion, reasonable esthetics and marginal seal ${ }^{36}$. The setting reactions of conventional GI and RMGI are similar, which begin with acid-base reactions and fluoride releases from the setting reaction as a byproduct ${ }^{37}$. Bonding to dental hard tissues by chemical reaction occurs where carboxylic components of cement react with calcium in enamel and dentin ${ }^{38-40}$. The adhesion mechanism is weak, resulting in low bond strength between the GI and the dentin ${ }^{41}$, because of the smear layer, which may interfere with the adhesion mechanism ${ }^{38}$.

In contrast to that for GI, the RMGI are produced by the addition of monomer which is about $4-6 \%^{39,42}$, leading to improved working time and bond strength ${ }^{42}$, which may explain why RMGI showed higher shear bond strength than GI, but, RMGI require surface pretreatment in order to remove the smear layer before the placement ${ }^{43}$ and thus overcome the drawbacks and increase the bonding ${ }^{41,44}$, because when removing the smear layer before applying the restorative material, the surface wetting ability is improved, resulting in material tag formation, which may explain why the bond prep mode showed higher shear bond strength than the cutting mode with both materials, where bond prep mode cause selective etching with no smear layer. 


\section{CONCLUSION}

As regards the results of the current laboratory study, it can be concluded that:

1) Er,Cr:YSGG laser have adverse effect on the adhesion of RMGI and GI.

2) Bond prep mode is better than cutting mode.

3) RMGI is preferred than GI clinically.

\section{REFERENCES}

1. Yildrim T, Kerim Ayar M, Yesilyurt C. Influence of different Er,Cr:YSGG laser parameters on long-term dentin bond strength of self-etch adhesive. Lasers Med Sci. 2015; 30:2363-2368.

2. Murdoch-Kinch CA, McLEAN ME. Minimally invasive dentistry. J Am Dent Assoc. 2003; 134(1):87-95.

3. De Moor R, Delmé K. Laser-assisted cavity preparation and adhesion to erbium-lased tooth structure: part 1. Laser-assisted cavity preparation. J Adhes Dent. 2009; 11(6):427-438.

4. Hadley J, Young DA, Eversole LR, Gornbein JA. A laserpowered hydrokinetic system: for caries removal and cavity preparation.J Am Dent Assoc. 2000; 131(6):777-785.

5. De Moor R, Delmé K. Laser-assisted cavity preparation and adhesion to erbium-lased tooth structure, part 2: present-day adhesion to erbium-lased tooth structure in permanent teeth. J Adhes Dent. 2010; 12(2):91-102.

6. Shahabi S, Chiniforush N, Bahramian H,Monzavi A, Baghalian A, Kharazifard MJ. The effect of erbium family laser on tensile bond strength of composite to dentin in comparison with conventional method. Lasers Med Sci. 2013; 28(1):139-142.

7. Ramos TM, Ramos-Oliveira TM, Moretto SG, de Freitas PM, Esteves-OliveiraM, de Paula EC. Microtensile bond strength analysis of adhesive systems to Er: YAG and Er, Cr: YSGG lasertreated dentin. Lasers Med Sci. 2014; 29(2):565-573.

8. Lin S, Caputo AA, Eversole LR, Rizoiu I. Topographical characteristics and shear bond strength of tooth surfaces cut with a laser-powered hydrokinetic system. J Prosthet Dent. 1999; 82(4):451-455.

9. Lee B-S, Lin P-Y, ChenM-H, Hsieh T-T, Lin C-P, Lai J-Y, LanW-H. Tensile bond strength of Er, Cr: YSGG laser-irradiated human dentin and analysis of dentin-resin interface. Dent Mater. 2007; 23(5):570-578.
10. Carvalho AO, Reis AF, de Oliveira MT, de Freitas PM, Aranha ACC, Eduardo CP, Giannini M. Bond strength of adhesive systems to Er, Cr: YSGG laser-irradiated dentin. Photomed Laser Surg. 2011; 29(11):747-752.

11. Cardoso MV, Coutinho E, Ermis RB, Poitevin A, Van Landuyt K, De Munck J, Carvalho R, Lambrechts P, Van Meerbeek B. Influence of Er, Cr: YSGG laser treatment on the microtensile bond strength of adhesives to dentin. $\mathrm{J}$ Adhes Dent. 2008; 10(1):25-33.

12. Adebayo O, Burrow M, Tyas M, Palamara J. Effect of tooth surface preparation on the bonding of self-etching primer adhesives. Oper Dent. 2012; 37(2):137-149.

13. Apel C, Schäfer C, Gutknecht N. Demineralization of Er:YAG and Er,Cr:YSGG laser-prepared enamel cavities in vitro. Caries Res. 2003; 37(1):34-7.

14. Sungurtekin E, Öztaş N. The effect of erbium, chromium:yttrium-scandium-galliumgarnet laser etching on marginal integrity of a resin-based fissure sealant in primary teeth. Lasers Med Sci. 2010; 25(6):841-7.

15. Shirani F, Birang R, Malekipur MR, Zeilabi A, Shahmoradi M, Kazemi S, et al. Adhesion to Er: YAG laser and bur prepared root and crown dentine. Aust Dent J. 2012; 57(2):138-43.

16. Zhang S, Chen T, Ge LH. Scanning electron microscopy study of cavity preparation in deciduous teeth using the Er: YAG laser with different powers. Lasers Med Sci. 2012; 27(1):141-4.

17. Dunn WJ, Davis JT, Bush AC. Shear bond strength and SEM evaluation of composite bonded to Er: YAG laser-prepared dentin and enamel. Dent Mater 2005; 21(7):616-24.

18. Wanderley RL, Monghini EM, Pecora JD, Palma-Dibb RG, Borsatto MC. Shear bond strength to enamel of primary teeth irradiated with varying Er: YAG laser energies and SEM examination of the surface morphology: An in vitro study. Photomed Laser Surg 2005; 23(3):260-7.

19. Bahrololoomi Z, Ghafourifard R. Shear Bond Strength of Primary Teeth Dentin Irradiated with Different Erbiumdoped Yttrium Aluminium Garnet Laser Energies and Scanning Electron Microscope Study of Dentin Morphology. J Inter Oral Health 2016; 8(10):943-947.

20. Gurgan S, Kiremitci A, Cakir FY, Gorucu J, Alpaslan T, Yazici E, et al. Shear bond strength of composite bonded to Er,Cr: YSGG laser-prepared dentin. Photomed Laser Surg 2008; 26(5):495-500. 
21. Visuri SR, Gilbert JL, Wright DD, Wigdor HA, Walsh JT Jr. Shear strength of composite bonded to Er: YAG laserprepared dentin. J Dent Res. 1996; 75(1):599-605.

22. Mahmodian J, Afshar H, Darvish H, FekrAzad R. Comparison between shear bond strength of composite resin following surface conditioning with $\mathrm{Er} \mathrm{Cr}$ YSGG laser and acid etch on the enamel surface in primary canines. J Islamic Dent Assoc Iran. 2011; 23(2):105-9.

23. Ateyah NZ, Elhejazi AA. Shear bond strengths and microleakage of four types of dentin adhesive materials. J Contemp Dent Prac 2004; 5:1-8.

24. Scatena C, Torres CP, Gomes-Silva JM, Contente MM, Pécora JD, Palma-Dibb RG, et al. Shear strength of the bond to primary dentin: Influence of Er: YAG laser irradiation distance. Lasers Med Sci 2011;26(3):293-7.

25. Hossain M, Nakamura Y, Yamada Y, Suzuki N, Murakami Y, Matsumoto K. Analysis of surface roughness of enamel and dentin after Er,Cr: YSGG laser irradiation. J Clin LaserMed Surg 2001;19(6):297-303.

26. Hibst R, Keller U. Experimental studies of the application of the Er: YAG laser on dental hard substances: I. Measurement of the ablation rate. Lasers Surg Med 1989; 9(4):338-44.

27. Wanderley RL, Monghini EM, Pecora JD, Palma-Dibb RG, Borsatto MC. Shear bond strength to enamel of primary teeth irradiated with varying Er: YAG laser energies and SEM examination of the surface morphology: An in vitro study. Photomed Laser Surg 2005;23(3):260-7.

28. Sung EC, Chenard T, Caputo AA, Amodeo M, Chung EM, Rizoiu IM. Composite resin bond strength to primary dentin prepared with Er, Cr: YSSG laser. J Clin Pediatr Dent 2005;30(1):45-9.

29. Armengol V, Jean A, Rohanizadeh R, Hamel H. Scanning electron microscopic analysis of diseased and healthy dental hard tissues after Er: YAG laser irradiation: In vitro study. J Endod 1999;25(8):543-6.

30. Kataumi M, Nakajima M, Yamada T, Tagami J. Tensile bond strength and SEM evaluation of Er: YAG laser irradiated dentin using dentin adhesive. Dent Mater J 1998;17(2):125-38. 19.

31. Burnett LH Jr, Conceição EN, Pelinos JE, Eduardo CD. Comparative study of influence on tensile bond strength of a composite to dentin using Er: YAG laser, air abrasion, or air turbine for preparation of cavities. J Clin Laser Med Surg 2001;19(4):199-202.

32. Sakakibara Y. A study on bond strength to dentin irradiated by erbium: YAG laser. Jpn J Conserv Dent 1998; 41:207-19.

33. Ceballo L, Toledano M, Osorio R, Tay FR, Marshall GW. Bonding to Er-YAG-laser-treated dentin. J Dent Res 2002;81(2):119-22.

34. Bachmann L, Diebolder R, Hibst R, Zezell DM. Changes in chemical composition and collagen structure of dentine tissue after erbium laser irradiation. Spectrochim Acta A Mol Biomol Spectrosc 2005;61: 2634-2639.

35. Korkmaz Y, Ozel E, Ozge BicerN Attar C. Influence of different conditioning methods on the shear bond strength of novel light-curing nano-ionomer restorative to enamel and dentin.Lasers Med Sci 2010; 25:861-866.

36. Korkmaz Y, Baseren M (2008) Effect of antibacterial varnishes applied to root dentin on shear bond strength of tooth-colored restorative materials. Oper Dent 33:65-71.

37. Burgess JO, Gallo JR (2002) Treating root-surface caries. Dent Clin North Am 46:385-404.

38. Lin A, McIntyre NS, Davidson RD (1992) Studies on the adhesion of glass-ionomer cements to dentin. J Dent Res 71:1836-1841.

39. Yap AU, Tan AC, Goh AT, Goh DC, Chin KC (2003) Effect of surface treatment and cement maturation on the bond strength of resin-modified glass ionomers to dentin. Oper Dent 28:728-733 32.

40. Godoy-Bezerra J, Vieira S, Oliveira JH, Lara F (2006) Shear bond strength of resin-modified glass ionomer cement with saliva present and different enamel pretreatments. Angle Orthod 76:470-474.

41. Powis DR, Folleras T, Merson AS, Wilson AD (1982) Improved adhesion of a glass ionomer cement to dentin and enamel. J Dent Res 61:1416-1422.

42. Nicholson JW (1998) Chemistry of glass-ionomer cements: a review. Biomaterials 19:485-494.

43. Pereira PN, Yamada T, Inokoshi S, Burrow MF, Sano H, Tagami J (1998) Adhesion of resin-modified glass-ionomer cement using resin-bonding systems. J Dent 26:479-485.

44. Kerber LJ, Donly KJ (1993) Caries inhibition by fluoridereleasing primers. Am J Dent 6:216-218 